\title{
Sludge Fiber Waste and Kraft Lignin Powder as Fillers in Polylactic Acid Biocomposites: Physical, Mechanical, and Thermal Properties
}

\author{
Thiago Souza da Rosa ${ }^{1, *}$, Rosilani Trianoski ${ }^{2}$, Franck Michaud ${ }^{3}$, Fábio Yamashita ${ }^{4}$ and Setsuo Iwakiri ${ }^{2}$ \\ 1 Programa de Pós-Graduação em Engenharia Florestal, Universidade Federal do Paraná, \\ 632, Av. Prefeito Lothário Meissner, Curitiba 80210-170, Brazil \\ 2 Departamento de Engenharia e Tecnologia Florestal, Universidade Federal do Paraná, \\ 632, Av. Prefeito Lothário Meissner, Curitiba 80210-170, Brazil; rosillani@gmail.com (R.T.); \\ setsuo.ufpr@gmail.com (S.I.) \\ 3 LIMBHA, Ecole Supérieure du Bois, 7, Rue Christian Pauc, 44000 Nantes, France; \\ franck.michaud@esb-campus.fr \\ 4 Departamento de Ciência e Tecnologia de Alimentos, Universidade Estadual de Londrina, \\ Rodovia Celso Garcia Cid-Pr 445 Km 380, Londrina 86057-970, Brazil; fabioy@uel.br \\ * Correspondence: thiagosouzadarosa@gmail.com; Tel.: +55-419-9248-9290
}

check for updates

Citation: Rosa, T.S.d.; Trianoski, R.; Michaud, F.; Yamashita, F.; Iwakiri, S. Sludge Fiber Waste and Kraft Lignin Powder as Fillers in Polylactic Acid Biocomposites: Physical, Mechanical, and Thermal Properties. Polymers 2021, 13, 672. https://doi.org/ $10.3390 /$ polym 13050672

Academic Editors: Sunil Kumar Ramamoorthy and Dimitrios Bikiaris

Received: 17 November 2020

Accepted: 16 December 2020

Published: 24 February 2021

Publisher's Note: MDPI stays neutral with regard to jurisdictional claims in published maps and institutional affiliations.

Copyright: (c) 2021 by the authors. Licensee MDPI, Basel, Switzerland. This article is an open access article distributed under the terms and conditions of the Creative Commons Attribution (CC BY) license (https:/ / creativecommons.org/licenses/by/ $4.0 /)$.

\begin{abstract}
In this investigation, sludge fibre waste (SFW) and Kraft lignin powder (KLP) are introduced into polylactic acid (PLA) matrix biocomposites. These alternative materials allow for both the reuse of fibre waste from paper mill sludge and a reduction in the amount of high-cost biopolymer used in the same volume. Proportions from 10 to $40 \mathrm{wt}$. $\%$ of SFW with the addition of $2.5 \%$ and $5 \%$ of KLP are incorporated in PLA by extrusion and injection moulding. The thermogravimetric properties, water absorption, tensile and flexural properties, and morphology of the fabricated biocomposites were investigated. According to the results, KLP contributes to thermically stabilising the loss resulting from the incorporation of SFW. Flexural and tensile tests reveal a more pronounced decrease in strength with an SFW ratio above $10 \%$. The modulus of elasticity increases significantly with an SFW ratio above $20 \%$. The strength properties are stabilised with the addition of 5\% KLP. The addition of KLP presents a tendency to reduce water absorption obtained by the incorporation of SFW into biocomposites. Scanning electron micrographs evidence that KLP improves the interfacial adhesion by reducing the voids between fibres and PLA.
\end{abstract}

Keywords: bio-based polymers; PLA; by-products; value-added products

\section{Introduction}

The generation of solid waste from paper mill sludge is increasing and it is estimated that the global waste production ranges between 0.5 and 1.3 million tons per year [1]. Around $25 \%$ of waste from paper mills stored in sludges is intended for landfilling, land spreading, and composting [2-4]. In general, sludge wastes are considered non-hazardous wastes that show high alkalinity and are basically composed of organic matter, mainly cellulose fibers, and inorganic compounds, such as kaolin, talc, and calcium carbonate [3,5,6].

With regards to safety and the environment, the sludge waste from paper mills can be reused with the generation of new higher value-added products, which reduces landfill disposal [7]. Recycling sludge waste is still a challenge, but can bring several benefits and opportunities with new application solutions [8]. Indeed, different types of composite materials are being generated by fibers from sludge fiber waste (SFW), which are lightweight, durable, non-abrasive, renewable, biodegradable, and recyclable products, allowing competition with products, mainly crude-oil derivative-based with less availability or environmental disadvantages [9]. 
The incorporation of short natural fibers as reinforcements or fillers, such as those present in sludges, is being commonly applied in thermoplastic composites as a natural alternative to improve the mechanical and thermal properties of the products while still providing low costs and density [10]. Furthermore, the mineral components present in sludges have been used as fillers in thermoplastic products, mainly polylactic acid (PLA)based composites with different or various loadings, thereby reducing the production costs and speeding up PLA crystallization [11].

PLA has become a sustainable alternative for replacing commodity polymers because it presents some advantages over polymers derived from petroleum, such as the low emission of greenhouse gases and a small amount of energy usage, excellent melt processability, low flammability, and renewability, especially where biodegradability is required [12-17]. However, PLA shows some disadvantages, including high costs, low toughness, low ductility, and poor thermal stability $[18,19]$. Although PLA is considered to be strongly hydrophobic $[14,20,21]$, it has a certain degree of affinity with water due to the ester, oxirane, and hydroxyl groups present in its composition [22], which may undergo hydrolytic degradation in the presence of water [23].

Combining SFW and PLA biopolymers is a good alternative to address the discussed challenges. Compatibility, coupling, and adhesion quality remain key points to benefit from a composite's raw materials. One way to improve the limitations of PLA is the incorporation of fillers, such as lignin, which allows us to improve properties while maintaining the objective of achieving bioresource materials. Lignin has been studied and added in composites due to the potential interaction between the hydroxyl and carboxyl groups of lignin and PLA. [24]. Therefore, lignin has been investigated as a biocompatibilizer between natural fibers and polymer matrices, thereby improving interfacial adhesion when used up to a specific ratio [25-27].

In the current investigation, SFW and kraft lignin powder (KLP) from a pulp and paper mill are used to fabricate PLA matrix biocomposites. The effect of the SFW and KLP ratio on the mechanical, physical, and thermal properties of biocomposites is investigated. The adhesion quality between the PLA and SFW is examined and investigated under scanning electron micrographs on a tensile breaking point of biocomposites.

\section{Materials and Methods}

\subsection{Materials}

The biopolymer PLA 3052D with a melt flow rate of $14 \mathrm{~g} / 10 \mathrm{~min}\left(210^{\circ} \mathrm{C}\right.$ and $\left.2.16 \mathrm{~kg}\right)$ and a density of $1.24 \mathrm{~g} \cdot \mathrm{cm}^{-3}$ was purchased from Nature Works LLC (Minnetonka, MN, USA). The SFW and KLP were supplied from a paper mill located in Sao Paulo, Brazil, obtained from kraft process sludge (chips from Eucalyptus sp.).

SFW was dried in an oven at $103^{\circ} \mathrm{C}$ for $72 \mathrm{~h}$ and then ground in a Wiley mill to pass a 32-mesh $(0.50 \mathrm{~mm})$ screen in order to obtain a thin homogeneous material. The amount and composition of inorganic matter content in SFW was previously determined in Rosa et al. [28].

\subsection{Processing of Biocomposites}

Biocomposites were fabricated using a counter-rotating and interpenetrating twinscrew extruder (D-20-BGM, Sao Paulo, Brazil) with a diameter of $20 \mathrm{~mm}, \mathrm{~L} / \mathrm{D}$ ratio of 34 , speed of $120 \mathrm{rpm}$, and 5 heating zones with a temperature profile from $100{ }^{\circ} \mathrm{C}$ at the feeding zone to $200{ }^{\circ} \mathrm{C}$ at the die nozzle. The PLA pellets were vacuum dried at $50 \pm 2{ }^{\circ} \mathrm{C}$ for $72 \mathrm{~h}$ and the SFW and KLP were dried at $103 \pm 2{ }^{\circ} \mathrm{C}$ to constant mass before extrusion. The materials were mixed manually before extrusion by weight proportion according to the experimental design (Table 1) by adding KLP firstly into the SFW and finally the mixture into PLA. The materials were blended through an extrusion process in order to prepare biocomposite pellets suitable for injection molding. The injection molding was performed by a bench injector (AX16III-AX Plásticos, Sao Paulo, Brazil) with a volume, velocity, and fill time injection of $22 \mathrm{~cm}^{3}, 30 \mathrm{~cm}^{3} \mathrm{~s}^{-1}$, and $5.5 \mathrm{~s}$, respectively. 
The barrel and mold temperature of the injection molding machine were set at 200 and $25^{\circ} \mathrm{C}$, respectively. The injection-molded specimens were obtained according to standard ASTM D638-14 [29] type IV $(115 \times 19 \times 6 \times 4 \mathrm{~mm}$, for length overall, width overall, width of narrow section, and thickness, respectively) for tensile tests conjugated with a bar for flexural tests $(115 \times 12.5 \times 4 \mathrm{~mm}$ for length, width, and thickness, respectively). The specimens were used for evaluation of the physical, mechanical, and thermal properties of the biocomposites.

Table 1. Experimental design.

\begin{tabular}{ccc}
\hline & Proportion (wt. \%) & \\
\hline PLA & SFW & KLP \\
\hline 100 & 0 & 0 \\
95 & 5 & 0 \\
90 & 10 & 0 \\
80 & 20 & 0 \\
70 & 30 & 0 \\
60 & 40 & 0 \\
92.5 & 5 & 2.5 \\
87.5 & 10 & 2.5 \\
77.5 & 20 & 2.5 \\
67.5 & 30 & 2.5 \\
57.5 & 40 & 2.5 \\
90 & 5 & 5 \\
85 & 10 & 5 \\
75 & 20 & 5 \\
65 & 30 & 5 \\
55 & 40 & 5 \\
\hline
\end{tabular}

\subsection{Thermal Characterization}

The thermal properties (thermogravimetric and its derivatives) of the SFW, KLP, PLA (neat PLA) and the developed biocomposites were investigated using simultaneous thermal analyzer (STA 449 F3 Jupiter-Netzsch, Selb, Germany). Samples of $\sim 5 \mathrm{mg}$ were heated in $\mathrm{Al}_{2} \mathrm{O}_{3}$ crucibles at a rate of $10{ }^{\circ} \mathrm{C} / \mathrm{min}$ in the range of $20-800{ }^{\circ} \mathrm{C}$ under a nitrogen flow of $50 \mathrm{~mL} / \mathrm{min}$.

\subsection{Mechanical Characterization}

The mechanical properties of the developed biocomposites were evaluated. Tensile tests were performed in a computerized universal testing machine (DL 20000-EMIC/ INSTRON, São Jose dos Pinhais, Brazil), with a load cell of $20 \mathrm{kN}$ and a test speed of $5 \mathrm{~mm} / \mathrm{min}^{-1}$, according to ASTM D638-14 [29]. The flexural tests were conducted at a crosshead speed of $1 \mathrm{~mm} / \mathrm{min}^{-1}$ and a span length of $56 \mathrm{~mm}$, according to ASTM D790-17 [30].

\subsection{Water Absorption}

For water absorption tests, the specimens were vacuum dried VT-5042 EK-Heraeus, Hanau, Germany) at $50 \pm 2{ }^{\circ} \mathrm{C}$ for $24 \mathrm{~h}$ and then the dry weight was measured. The samples were dipped into a glass beaker containing distilled water at $23 \pm 1{ }^{\circ} \mathrm{C}$. The weight of the immersed specimens was measured after 2, 24, 168, and $504 \mathrm{~h}$ (constant weight/saturation), according to ASTM D570-98 [31].

\subsection{Morphological Characterization}

The breaking point surfaces of the tensile test samples were metalized with gold for grounding and analyzed using scanning electron microscopy (SEM) with a Tescan Vega $3 \mathrm{LMU}$ (Brun, Czech) under a low vacuum (30 Pa) with an ion beam power of $15 \mathrm{kV}$. 


\subsection{Statistical Analysis}

At least ten test specimens were tested for a total of three batches of each composition. To assess the effect of incorporating SFW and KLP into PLA biocomposites, the data from the physical and mechanical tests were subjected to statistical analysis using multivariate tests. The hypothesis was tested that the compositions have no significant effect on these properties through multivariate analysis of variance (MANOVA), in which the Wilks test was evaluated. This analysis was applied because the variables are correlated. Tukey's post hoc test was applied to identify groups of means for each variable. The analyses were performed at the $5 \%$ level of significance.

\section{Results}

\subsection{Biocomposite Characteristics}

The thermal behavior of the PLA, SFW, KLP, and biocomposites was studied by thermogravimetry. From Figure 1A, PLA shows an onset temperature of $332{ }^{\circ} \mathrm{C}$ and only one degradation phase, resulting in greater thermal stability than the SFW and KLP. The SFW presents two degradation phases (Figure 1B), the first one with the maximum mass loss at $330{ }^{\circ} \mathrm{C}$ due to cellulose and hemicellulose pyrolysis [2,32] and the second one at a maximum mass loss rate of $679{ }^{\circ} \mathrm{C}$ related to the decomposition of $\mathrm{CaCO}_{3}$ [33,34]. From the second stage of mass loss present on the SFW thermogravimetric curve between 620 and $800{ }^{\circ} \mathrm{C}$, corresponding to the decomposition of $\mathrm{CaCO}_{3}$, it was possible to estimate the amount of this mineral present in the SFW [35,36]. The mass difference was $15.34 \%$ due to the release of $\mathrm{CO}_{2}$ from $\mathrm{CaCO}_{3}$, thus, stoichiometrically, the estimated amount of $\mathrm{CaCO}_{3}$ present in the SFW was $34.9 \%$. The sum of amounts of $\mathrm{CaCO}_{3}$ and the first stage of degradation of $43.8 \%$ (attributed to cellulose and organic compound decomposition) does not correspond to $100 \%$ of the total. The difference of $21.3 \%$ was due to another inorganic compound present in the SFW (quartz), which is thermally stable up to the temperature of $800^{\circ} \mathrm{C}$.

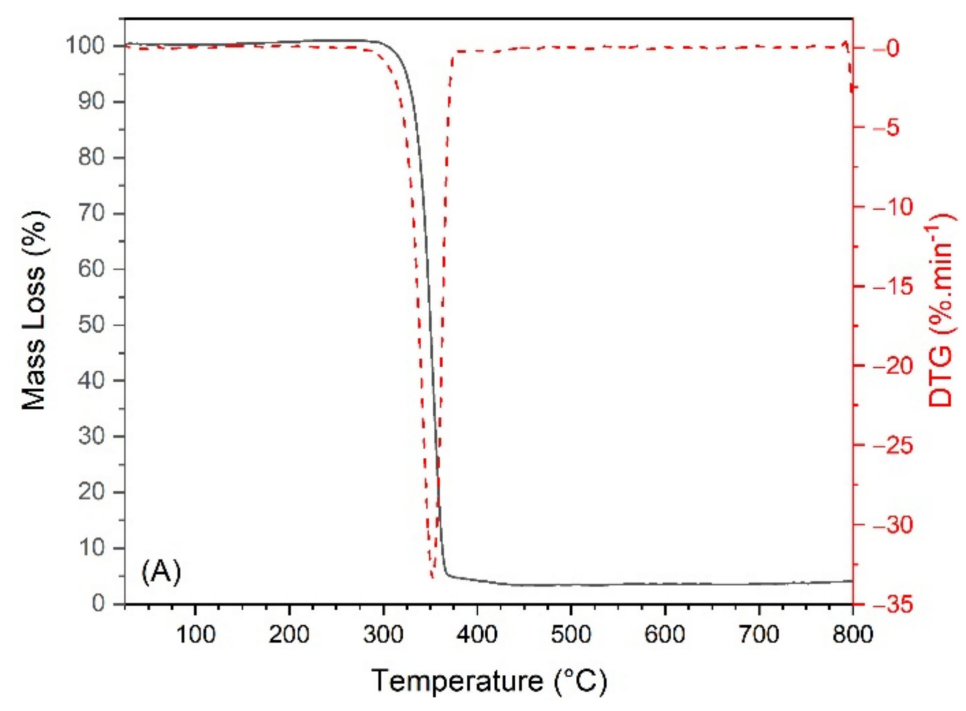

Figure 1. Cont. 

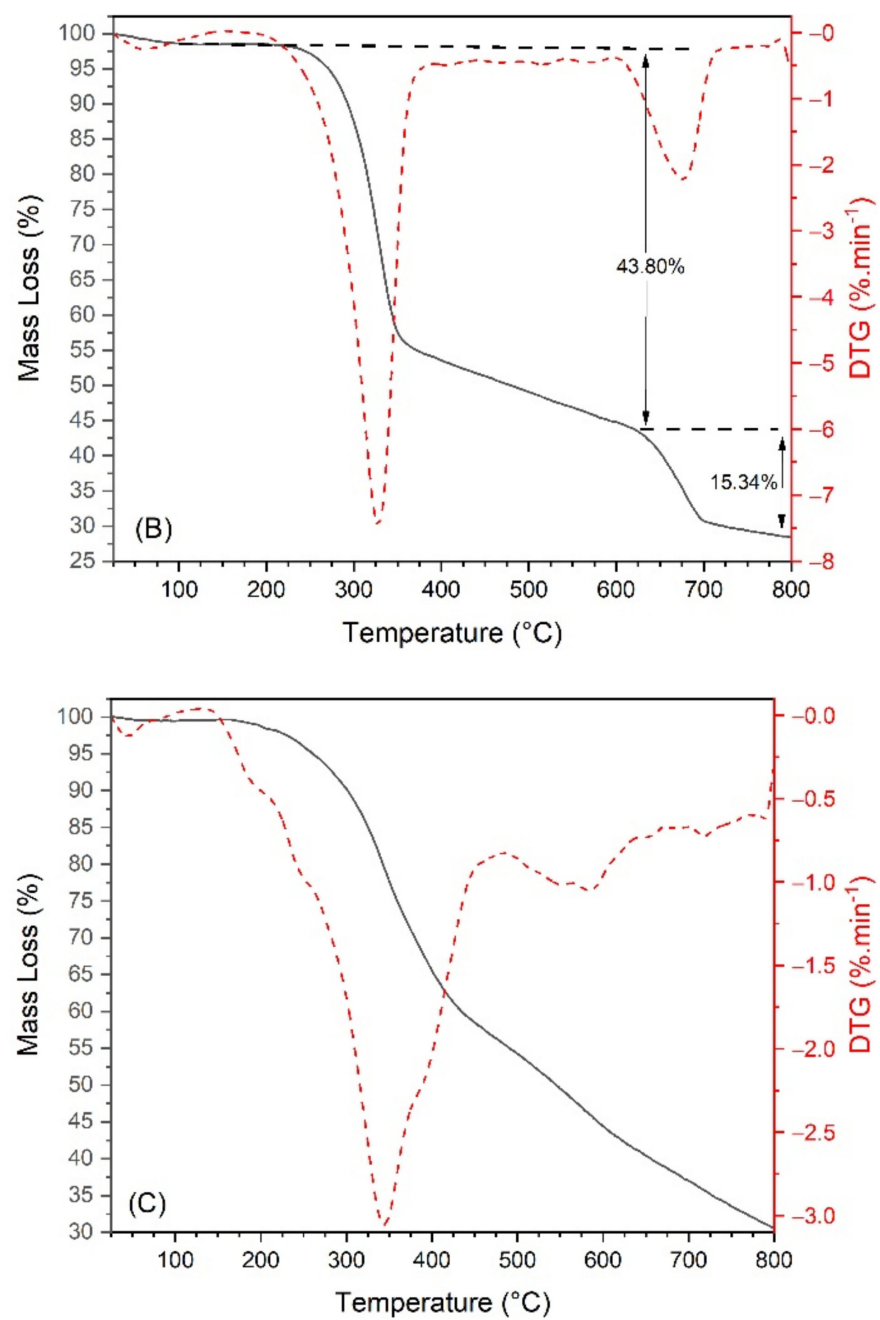

Figure 1. Thermogravimetric curves of (A) polylactic acid (PLA), (B) sludge fiber waste (SFW), and (C) kraft lignin powder (KLP).

The higher KLP mass loss occurred between 300 and $500{ }^{\circ} \mathrm{C}$ (Figure $1 \mathrm{C}$ ) and is related to the fragmentation of inter-unit linkage and the decomposition of products having a phenolic hydroxyl group [12,37]. KLP reached a maximum mass loss rate at $344{ }^{\circ} \mathrm{C}$, presenting a higher char residue content at $800{ }^{\circ} \mathrm{C}(30.67 \%)$ among the raw materials. The high char residue is correlated to the carbon yield, which is not entirely decomposed in an $\mathrm{N}_{2}$ atmosphere by the absence of $\mathrm{O}_{2}$ and no oxidation [38].

The thermogravimetric curves of the biocomposites show lower thermal stability than PLA (Figure 2). Three main mass losses could be observed, mainly in the biocomposites with a higher amount (40\%) of incorporated SFW. The first peak was between 200 and $280{ }^{\circ} \mathrm{C}$, indicating the cellulose decomposition, and it is represented in the DTG curve as the sharpest peak. The second one between 280 and $370{ }^{\circ} \mathrm{C}$ is related to PLA decomposition and could be visualized on the DTG curve as a shoulder along with the first peak. The final loss could be observed at the end of the TG curve between 600 and $700{ }^{\circ} \mathrm{C}$, corresponding to $\mathrm{CaCO}_{3}$ decomposition present in the SFW appearing at the end of the DTG curve as the last pronounced peak. 

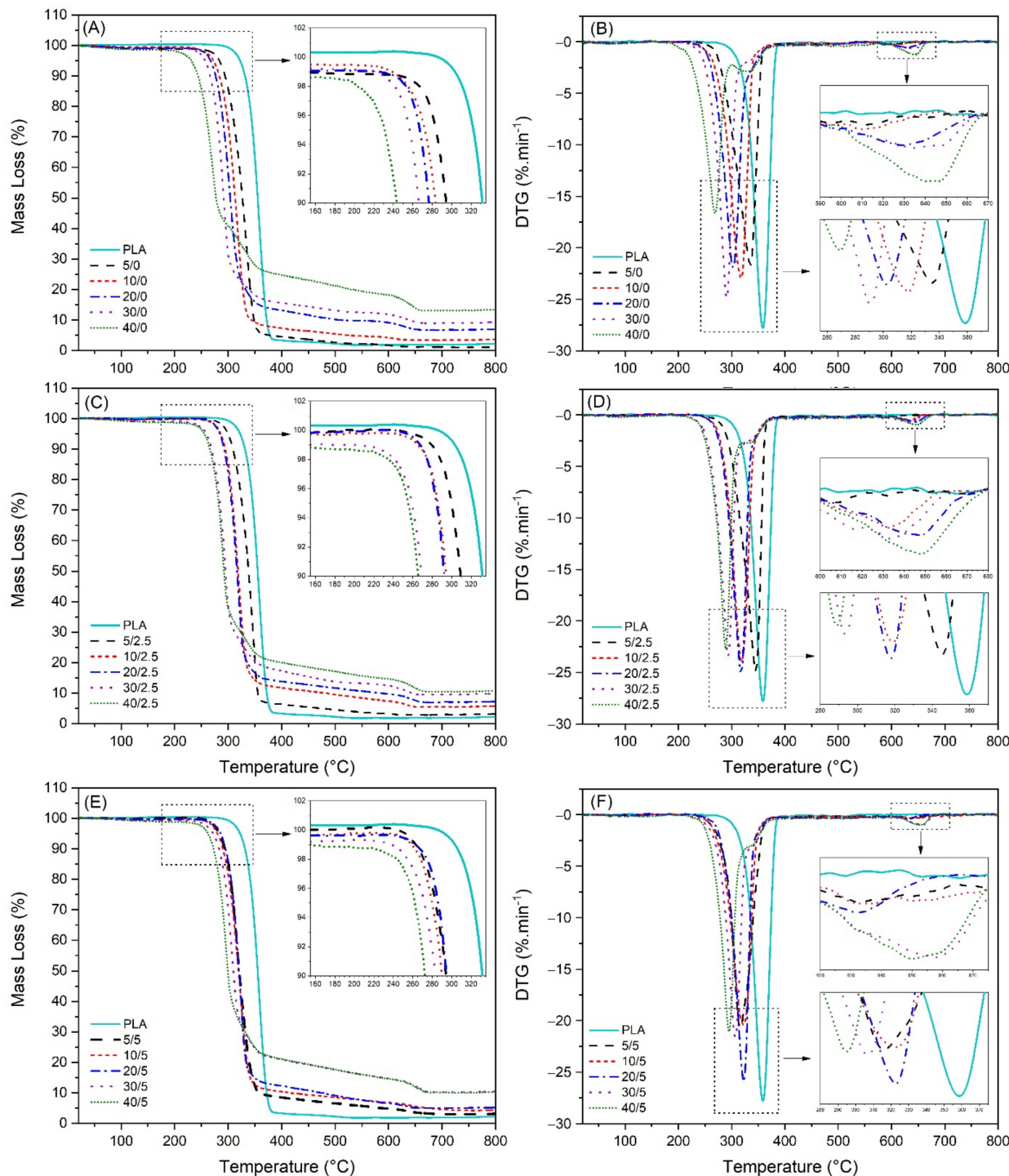

Figure 2. Thermogravimetric curves of biocomposites: (A) TG curves for compositions with no KLP, (B) DTG curves for compositions with no KLP, (C) TG curves for compositions with $2.5 \%$ KLP, (D) DTG curves for compositions with $2.5 \%$ KLP, (E) TG curves for compositions with 5\% KLP, (F) DTG curves for compositions with 5\% KLP.

Table 2 shows the main temperature characteristics of the biocomposites and the thermal stability could be analyzed by $\mathrm{T}_{\text {onset }}$. As can be seen, there was a clear trend in the biocomposite behavior without KLP incorporation, decreasing the thermal stability and increasing the char residue according to the proportion of SFW. This might be due to the decrease of the relative molecular weight of biocomposites with the incorporation of SFW in the PLA matrix. As can be previously observed in Figure 1B, the cellulose fibers contained in the SFW were thermally less stable than PLA, which may have resulted in a negative effect on the biocomposites. Even with the incorporation of low proportions of SFW (5\% and $10 \%$ ), the stability decreased by at least $10 \%$. This trend was minimized with the addition of $2.5 \%$ of KLP, increasing the stability of the biocomposite composed by $5 / 2.5$ at $4.27 \%$ and almost matched the stability of the biocomposites composed by $0 / 5,20 / 5,30 / 5$ and $40 / 5$. The addition of $2.5 \%$ KLP resulted in the increase of char residue in a general way; however, when $5 \%$ of KLP was added, there was the tendency to reduce the residue slightly. Indeed, the addition of lignin tended to increase the total char residue as previous results reported $[25,39,40]$. In that case, the heterogeneous dispersion of $\mathrm{CaCO}_{3}$ present in the SFW could have influenced mainly biocomposites with high amounts of incorporation, since this 
one may be present in a greater proportion with respect to the fibers in the SFW. In contrast, the addition of 5\% KLP improved the thermal stability of biocomposites except for the one containing 5\% SFW. The addition of 5\% KLP, in fact, brought the stability temperatures of the biocomposites closer each other, being able to maintain also similar amounts of residue. Lignin is an environmentally friendly flame-retardant additive that improves thermal oxidation stability due to the abundance of aromatic structures in its composition, yielding high carbon residues after combustion [41-43]. In this study, the addition of KLP as a stabilizer was able to increase or maintain the decomposition temperatures of the biocomposites.

Table 2. Some thermal characteristics of PLA, SFW, KLP, and biocomposites.

\begin{tabular}{ccccccc}
\hline Composition & $\mathbf{T}_{\text {onset }}\left({ }^{\circ} \mathbf{C}\right)$ & $\mathbf{T}_{\text {1max }}\left({ }^{\circ} \mathbf{C}\right)$ & $\mathbf{T}_{\text {2max }}\left({ }^{\circ} \mathbf{C}\right)$ & $\mathbf{C R}_{\text {T1max }}(\mathbf{\%})$ & $\mathbf{C R}_{\text {T2max }}(\mathbf{\%})$ & $\mathbf{C R}_{\mathbf{8 0 0}}(\mathbf{\%})$ \\
\hline PLA & 332 & 359 & - & 39.38 & - & 2.18 \\
SFW & 290 & 330 & 679 & 69.46 & 34.51 & 28.46 \\
KLP & 269 & 344 & 582 & 79.52 & 46.29 & 30.67 \\
$5 / 0$ & 298 & 335 & - & 32.91 & - & 1.20 \\
$10 / 0$ & 287 & 319 & 608 & 36.76 & 4.01 & 3.60 \\
20/0 & 278 & 302 & 627 & 53.88 & 8.03 & 6.98 \\
$30 / 0$ & 270 & 291 & 634 & 51.66 & 10.31 & 9.23 \\
$40 / 0$ & 241 & 269 & 640 & 62.82 & 15.19 & 13.40 \\
$5 / 2.5$ & 313 & 346 & - & 31.24 & - & 3.22 \\
$10 / 2.5$ & 295 & 319 & 632 & 48.78 & 7.80 & 5.77 \\
$20 / 2.5$ & 293 & 318 & 647 & 46.60 & 10.82 & 7.27 \\
$30 / 2.5$ & 272 & 293 & 632 & 55.43 & 11.78 & 9.78 \\
$40 / 2.5$ & 270 & 289 & 649 & 57.84 & - & 10.75 \\
$5 / 5$ & 294 & 316 & - & 59.27 & 6.01 & 3.16 \\
$10 / 5$ & 295 & 322 & 636 & 44.76 & 5.66 & 4.34 \\
$20 / 5$ & 298 & 323 & 632 & 43.05 & 11.45 & 5.21 \\
$30 / 5$ & 284 & 307 & 659 & 56.25 & 12.05 & 10.45 \\
$40 / 5$ & 275 & 295 & 649 & 59.86 & 10.27 \\
\hline
\end{tabular}

$\mathrm{T}_{1 \max }=$ maximum first peak temperature; $\mathrm{T}_{2 \max }=$ maximum second peak temperature; $\mathrm{CR}_{\mathrm{T} 1 \mathrm{max}}=$ charred residue at $\mathrm{T}_{1 \max } ; \mathrm{CR}_{\mathrm{T} 2 \max }=$ charred residue at $\mathrm{T}_{2 \max } ; \mathrm{CR}_{800}=$ charred residue at $800^{\circ} \mathrm{C}$.

\subsection{Water Absorption}

Water absorption (WA) of the biocomposites is shown in Figure 3, as well as the results of the multivariate analysis. The WA increased continuously with the time of immersion and reached equilibrium after $504 \mathrm{~h}$. The incorporation of SFW in PLA increased the WA of biocomposites proportionally to the SFW ratio (Figure 3A). The hydrophilic characteristics of cellulose and hemicellulose contained in SFW explain this phenomenon. In fact, as already mentioned in the literature, when the biocomposite is consolidated with high-fiber volume fractions, it results in the formation of clusters of connected material that are not completely isolated by the matrix that then remain on the surface, therefore becoming a point of percolation of water into the composite, thus providing continuous conduction paths of water by fibers [44,45].

Swelling of cellulose when exposed to water results in microcracking of the matrix, contributing to extended water paths and then more water penetration into the biocomposites, resulting in de-bonding between the fiber and the matrix [46]. However, the addition of KLP significantly reduced the WA up to $30 \%$ of SFW and showed an even more pronounced effect with $40 \%$ of SFW. The incorporation of KLP decreases the WA during the time (Figure 3B). KLP acts as a stabilizer or countermeasure effect in the gain of water caused by the addition of SFW. This effect on the WA, well known in lignocellulosic materials, such as wood cell walls, is due to the increase of hydrophobic aromatic rings of lignin such that these polar ends would interact favorably with the surfaces of cellulosic fibers, partially preventing WA in the composite [47-49]. 

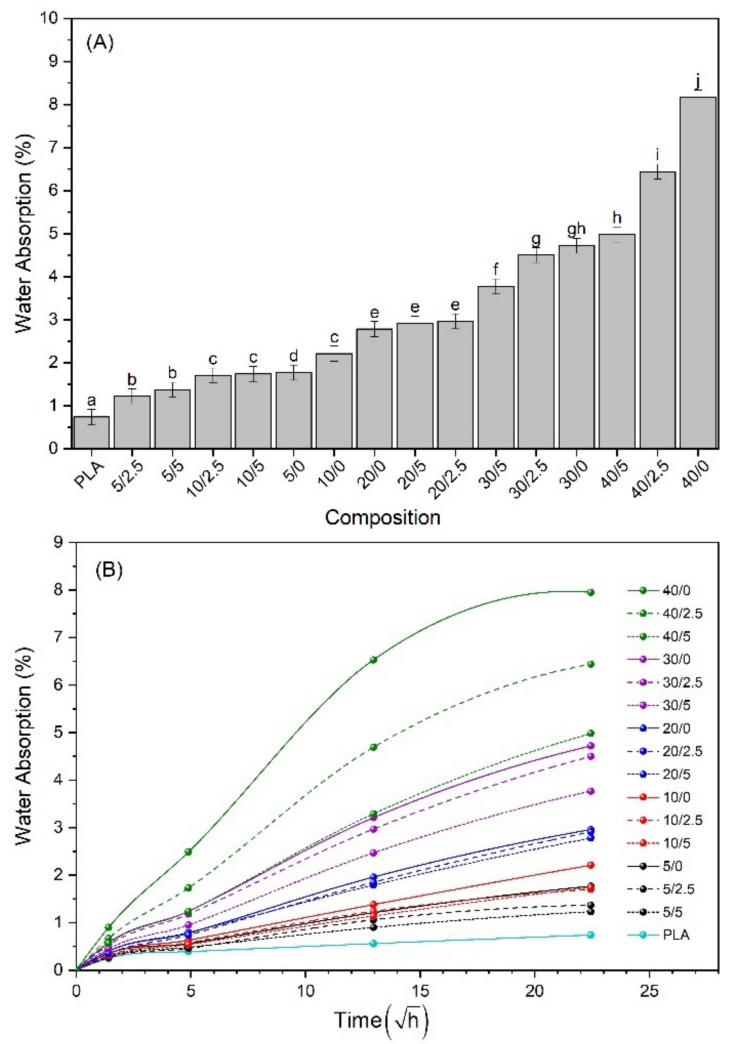

Figure 3. (A) Water absorption after saturation; (B) water absorption as a function of square root of the time.

\subsection{Mechanical Properties}

The tensile properties of the biocomposites and their multivariate analysis results are shown in Figure 4. It is observed that the tensile strength of the biocomposites decreased with the incorporation of SFW (Figure 4A). In this case, it can be stated that SFW does not have sufficient properties to satisfactorily improve the strength of the composites or the adhesion between SFW and PLA, and was not able to transfer the possible reinforcement properties of SFW to the biocomposites. However, the addition of $2.5 \%$ of KLP in the biocomposites with a low proportion of SFW ( $5 \%$ and $10 \%)$ balanced the strength, showing no significant differences compared with PLA. The increase of $2.5 \%$ to $5 \%$ lignin in the biocomposites with a low SFW content did not show significant losses in resistance. The great loss in strength began with the incorporation of $20 \%$ of SFW, decreasing drastically with $40 \%$. By adding $5 \%$ KLP, it was possible to maintain unaltered the resistance of biocomposites containing $20 \%$ to $40 \%$ SFW.

Similar behavior to the tensile strength is observed in the elongation at break (Figure 4B). The elongation of biocomposites decreased significantly with the incorporation of SFW from low proportions. In that case, the addition of KLP showed no significant improvement or loss of stabilization.

There were no significant changes in the Young's modulus (YM) of the biocomposites with the incorporation of SFW when compared with PLA (Figure 4C). However, the combination between the addition of $2.5 \%$ and $5 \%$ of KLP until $20 \%$ of SFW showed significantly higher values than PLA. The YM began to decrease slightly in biocomposites with $30 \%$ and $40 \%$ of SFW, even combined with the addition of KLP. In this case, the amount of KLP was insufficient to efficiently encapsulate the fibers and compensate the decrease caused by the high content of SFW. In addition, high proportions of SFW brought greater amounts of $\mathrm{CaCO}_{3}$, which may have a significant effect on the $\mathrm{YM}$, as explained for the tensile strength. Therefore, in order to reach the maximum performance of $\mathrm{YM}$, the incorporation threshold of $20 \% \mathrm{SFW}$ associated with $2.5 \%$ and $5 \%$ KLP is suggested. 

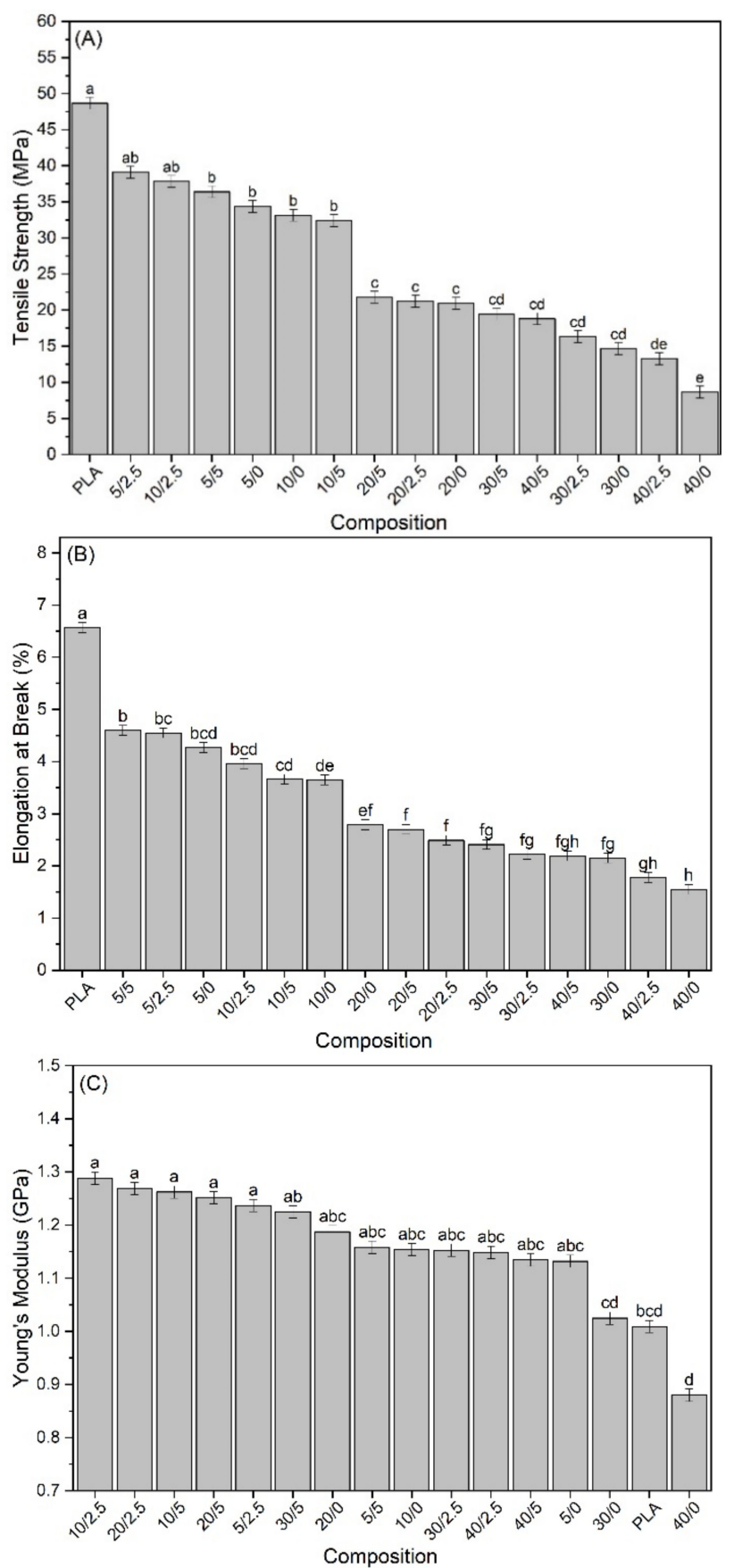

Figure 4. (A) Tensile strength; (B) Elongation at break, and (C) Young's modulus of biocomposites.

Modulus of rupture (MOR) shown a similar trend to that observed for tensile strength and elongation at break. Significant changes were not observed in MOR between PLA and the biocomposites with incorporation of $5 \%$ and $10 \%$ of SFW and the addition of KLP in both amounts. The tendency to reduce the tensile strength, elongation, and MOR with the incorporation of SFW in PLA composites was also observed in [50].

Significant losses in these properties could be associated with the weak interfacial adhesion between the hydrophilic cellulose fibers contained in the SFW and PLA matrix [39]. In addition, the high content of mineral compounds, mainly $\mathrm{CaCO}_{3}$ in SFW, may have contributed to reducing these properties. Betancourt and Cree (2017) observed similar behavior in their previous study with different loadings of $\mathrm{CaCO}_{3}$ in PLA composites and attributed these results to the agglomeration of high amounts of filler, leading to reduced bond strength between particles and an overall poorer dispersion. The weak bonding 
between $\mathrm{CaCO}_{3}$ particles and PLA is due to the aggregates acting as failure-initiation producing sites where micro-cracks can initiate by stress concentrations [8,51,52].

The positive effect of KLP was not observed on the modulus of elasticity (MOE) results (Figure 5B). In that case, the tensile modulus increased with the increase in the SFW content. Despite that, this increase was significant only with the incorporation of $20 \%$ or more of SFW when compared with PLA. In a general way, the biocomposites composed of $40 \%$ SFW presented significantly better results. It is known that the addition of fibrous fillers in a polymeric matrix generally increases the $\mathrm{MOE}$ of composites due to stress transfers from the PLA matrix to the stiffer fibers [53]. On this basis, the incorporation of SFW improved the stiffness of the biocomposites according to the proportion and significantly above $20 \%$, regardless of the amount of KLP added.
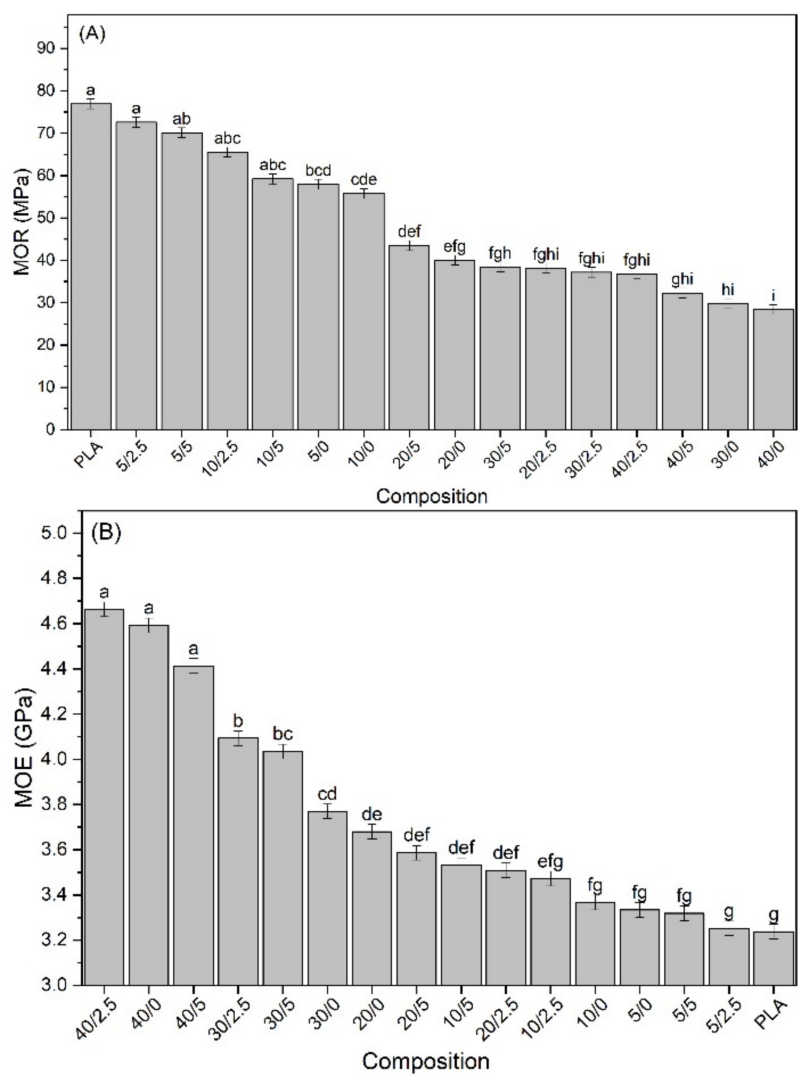

Figure 5. (A) Modulus of rupture and (B) modulus of elasticity of biocomposites.

In a general way, the results were inconclusive with the addition of SFW in biocomposites behaving only as a filler (due to high inorganic content) and showing poor adhesion. However, the addition of KLP shows evidence that it has the potential for promoting adhesion between cellulose content in SFW and PLA, besides enhancing hydrophobicity and having dispersive, lubricant, and thermal stability effects.

\subsection{SEM Analysis}

According to SEM micrographs it could be observed that the biocomposites produced without the addition of KLP showed low or the absence of adhesion between the fibers of SFW and the PLA, characterized by typical fiber pull-out (Figure 6a), which indicates a lack of interface (marked by arrows) due to the hydrophilic nature of SFW and the hydrophobic nature of the matrix [54]. 

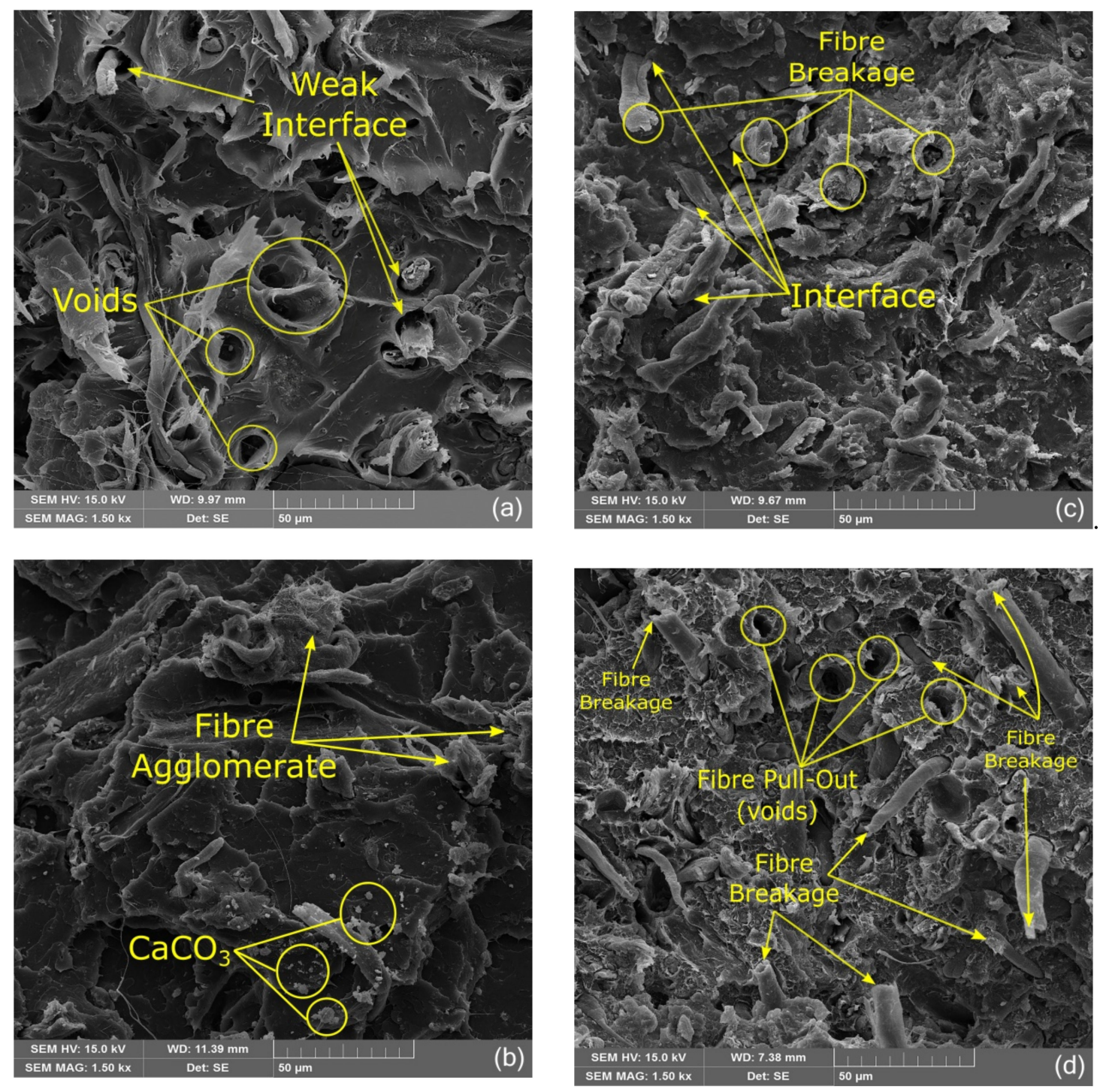

Figure 6. SEM micrographs of surfaces at the tensile rupture point: Evidence observed in (a) composition 10/0; (b) composition 30/0; (c) composition 20/2.5; (d) composition 40/5.

It is possible to identify voids (marked by circles), which indicate the presence of fibers that were not strength ruptured but pulled out from the matrix. This behavior is easier to observe at low SFW ratio composites (5\% and $10 \%)$, which could be explained in two different ways. In low proportions of SFW, there is a smaller amount of fibers that are agglomerated or awfully close together, which allows for better viewing.

The other explanation is because, in high proportions of SFW, the fibers occupy a larger volume of the composite and the matrix becomes brittle. When the tensile load is applied, the matrix surrounding the fibers shows a larger surface of contact, allowing for a better load transfer to the fibers (or even a local fiber network) that are then ruptured consecutively. In both ways, the transfer of stress from the matrix to the fibers was not completely efficient. The increase of proportion of SFW in the biocomposites without the addition of KLP increased consequently the number of regions with fiber agglomerates (Figure $6 \mathrm{~b}$ marked by arrows) and the amount of $\mathrm{CaCO}_{3}$ (Figure $6 \mathrm{~b}$ marked by circles) related to an ineffective dispersion of SFW in matrix. All these factors contribute to generating composites with inferior properties to those with KLP addition.

The addition of KLP in the biocomposites reduced part of the problems cited previously. The interface between fibers and PLA was improved with addition of $2.5 \%$ and $5 \%$ 
of KLP, and it could be visualized by better contact or a decrease of voids between fibers and matrix and the higher amount of broken fibers (Figure 6c). In addition, broken fibers could be detected as a result of stress absorption from the matrix. Indeed, the addition of KLP reduced the polarity at the interface, increasing interfacial adhesion, despite in some cases where the high amount of lignin could coat fibers and then decrease the physical anchoring between the fibers and matrix [26]. This behavior was more pronounced in biocomposites with the incorporation of low proportions of SFW, since higher amounts of SFW tended to generate agglomerates of fibers, as well as the same happening with high amounts of KLP.

This analysis confirms the best mechanical results were obtained by biocomposites with low proportions of SFW and the addition of KLP. The benefits of KLP addition could be observed to some extent, since the greater the amount of SFW and KLP incorporated $(40 \% / 5 \%)$, the lower the capacity of the polymer to cover all the fillers efficiently. In addition, due to this study using the maximum addition of 5\% KLP, there might not have been enough KLP available to fully cover all the fibers of SFW. Thus, some regions displaying good adhesion presented broken fibers (Figure $6 \mathrm{~d}$ marked by arrows), but in other ones, weak adhesion presented voids (Figure $6 \mathrm{~d}$ marked by circles) and consequently prejudiced the mechanical properties of the material.

\section{Conclusions}

It was concluded that the incorporation of SFW decrease the thermal stability of biocomposites; however, the addition of KLP had the opposite effect, contributing to stabilize and improve the lost resistance to heat.

The $\mathrm{CaCO}_{3}$ content in SFW significantly affected the reinforcing capacity of SFW, mainly with SFW ratio above $10 \%$.

The water absorption increased significantly and proportionally with the incorporated amount of SFW. The addition of KLP slightly prevented water absorption, but not significantly.

SEM micrographs revealed low or no adhesion between the fibers from SFW and the PLA in compositions without KLP added. In addition, KLP was able to improve the interfacial adhesion only in compositions with low SFW ratio. KLP also improved the performance of the biocomposite by acting as a flame retardant, dispersion or coupling agent, and reducing water absorption.

It was also concluded that SFW and KLP have great potential as a filler for PLA biocomposites, reducing costs due to the lower PLA content in the material, and offer a better destination for waste and by-products of paper mills, allowing them to produce a material with higher value added as lightweight and non-structural products, such as plants tubes and pots, and even interior parts for the automobile industry. Therefore, to better target these biocomposites in relation to their application, it is necessary to study and define the optimal ratio between SFW, KLP, and PLA.

Author Contributions: Conceptualization, T.S.d.R., F.M., and F.Y.; data curation, T.S.d.R.; formal analysis, T.S.d.R.; funding acquisition, R.T. and S.I.; investigation, T.S.d.R.; methodology, T.S.d.R. and F.Y.; project administration, R.T. and S.I.; resources, F.Y.; supervision, R.T., F.M., F.Y., and S.I.; validation, T.S.d.R.; visualization, T.S.d.R.; writing—original draft, T.S.d.R.; writing-review and editing, R.T. and F.M. All authors have read and agreed to the published version of the manuscript.

Funding: This research received funding from the Fundação da Universidade Federal do Paraná-FUNPAR.

Institutional Review Board Statement: Not applicable.

Informed Consent Statement: Not applicable.

Data Availability Statement: The data presented in this study are available on request from the corresponding author.

Conflicts of Interest: The authors declare no conflict of interest. 


\section{References}

1. Kinnarinen, T.; Golmaei, M.; Jernström, E.; Häkkinen, A. Separation, treatment and utilization of inorganic residues of chemical pulp mills. J. Clean. Prod. 2016, 133, 953-964. [CrossRef]

2. Rivera, J.A.; López, V.P.; Casado, R.R.; Hervás, J.-M.S. Thermal degradation of paper industry wastes from a recovered paper mill using TGA. Characterization and gasification test. Waste Manag. 2016, 47, 225-235. [CrossRef]

3. Bajpai, P. Management of Pulp and Paper Mill Waste; Springer International Publishing: London, UK, 2015; ISBN 978-3-319-11787-4.

4. Likon, M.; Trebe, P. Recent Advances in Paper Mill Sludge Management. In Industrial Waste; InTech: Rijeka, Croatia, 2012; pp. 73-90.

5. Simão, L.; Jiusti, J.; Lóh, N.; Hotza, D.; Raupp-Pereira, F.; Labrincha, J.A.; Montedo, O. Waste-containing clinkers: Valorization of alternative mineral sources from pulp and paper mills. Process. Saf. Environ. Prot. 2017, 109, 106-116. [CrossRef]

6. Fava, G.; Ruello, M.L.; Corinaldesi, V. Paper Mill Sludge Ash as Supplementary Cementitious Material. J. Mater. Civ. Eng. 2011, 23, 772-776. [CrossRef]

7. Monte, M.C.; Fuente, E.; Blanco, A.; Negro, C. Waste management from pulp and paper production in the European Union. Waste Manag. 2009, 29, 293-308. [CrossRef]

8. De Cademartori, P.H.G.; Claro, F.C.; Marinho, N.P.; Zanoni, P.R.S.; Magalhães, W.L.E. Co-production of thermoplastic composites with solid residue from enzymatic hydrolysis of recycled paper sludge. J. Clean. Prod. 2017, 162, 27-33. [CrossRef]

9. Leão, A.L.; Cherian, B.M.; De Souza, S.F.; Sain, M.; Narine, S.; Caldeira, M.S.; Toledo, M.A.S. Use of Primary Sludge from Pulp and Paper Mills for Nanocomposites. Mol. Cryst. Liq. Cryst. 2012, 556, 254-263. [CrossRef]

10. Yu, T.; Li, Y.; Ren, J. Preparation and properties of short natural fiber reinforced poly(lactic acid) composites. Trans. Nonferrous Met. Soc. China 2009, 19, s651-s655. [CrossRef]

11. Murariu, M.; Dubois, P. PLA composites: From production to properties. Adv. Drug Deliv. Rev. 2016, 107, 17-46. [CrossRef]

12. Gordobil, O.; Delucis, R.; Egüés, I.; Labidi, J. Kraft lignin as filler in PLA to improve ductility and thermal properties. Ind. Crops Prod. 2015, 72, 46-53. [CrossRef]

13. Raquez, J.-M.; Habibi, Y.; Murariu, M.; Dubois, P. Polylactide (PLA)-based nanocomposites. Prog. Polym. Sci. 2013, 38, 1504-1542. [CrossRef]

14. Xiao, L.; Wang, B.; Yang, G.; Gauthier, M. Poly(Lactic Acid)-Based Biomaterials: Synthesis, Modification and Applications. In Biomedical Science, Engineering and Technology; IntechOpen: Rijeka, Croatia, 2012; pp. 247-282.

15. Auras, R.; Harte, B.R.; Selke, S. An Overview of Polylactides as Packaging Materials. Macromol. Biosci. 2004, 4, 835-864. [CrossRef]

16. Oksman, K.; Skrifvars, M.; Selin, J.-F. Natural fibres as reinforcement in polylactic acid (PLA) composites. Compos. Sci. Technol. 2003, 63, 1317-1324. [CrossRef]

17. Mukherjee, T.; Kao, N. PLA Based Biopolymer Reinforced with Natural Fibre: A Review. J. Polym. Environ. 2011, 19, 714-725. [CrossRef]

18. Anwer, M.A.S.; Naguib, H.E.; Celzard, A.; Fierro, V. Comparison of the thermal, dynamic mechanical and morphological properties of PLA-Lignin \& PLA-Tannin particulate green composites. Compos. Part B Eng. 2015, 82, 92-99. [CrossRef]

19. Jamshidian, M.; Tehrany, E.A.; Imran, M.; Akhtar, M.J.; Cleymand, F.; Desobry, S. Structural, mechanical and barrier properties of active PLA-antioxidant films. J. Food Eng. 2012, 110, 380-389. [CrossRef]

20. Hendrick, E.; Frey, M. Increasing Surface Hydrophilicity in Poly(Lactic Acid) Electrospun Fibers by Addition of Pla-b-Peg Co-Polymers. J. Eng. Fibers Fabr. 2014, 9, 153-164. [CrossRef]

21. Wang, F.-F.; Sun, Z.; Yin, J.; Xu, L. Preparation, Characterization and Properties of Porous PLA/PEG/Curcumin Composite Nanofibers for Antibacterial Application. Nanomaterials 2019, 9, 508. [CrossRef]

22. Yew, G.; Yusof, A.M.; Ishak, Z.M.; Ishiaku, U. Water absorption and enzymatic degradation of poly(lactic acid)/rice starch composites. Polym. Degrad. Stab. 2005, 90, 488-500. [CrossRef]

23. Tham, W.L.; Ishak, B.T.P.; Mohd, Z.A.; Chow, W.S. Characterisation of Water Absorption of Biodegradable Poly(lactic Acid)/Halloysite Nanotube Nanocomposites at Different Temperatures. J. Eng. Sci. Technol. 2016, 12, 13-25.

24. Spiridon, I.; Tanase, C.E. Design, characterization and preliminary biological evaluation of new lignin-PLA biocomposites. Int. J. Biol. Macromol. 2018, 114, 855-863. [CrossRef]

25. Gordobil, O.; Egüés, I.; Llano-Ponte, R.; Labidi, J. Physicochemical properties of PLA lignin blends. Polym. Degrad. Stab. 2014, 108, 330-338. [CrossRef]

26. Luo, S.; Cao, J.; Sun, W. Evaluation of Kraft lignin as natural compatibilizer in wood flour/polypropylene composites. Polym. Compos. 2015, 38, 2387-2394. [CrossRef]

27. Polat, Y.; Stojanovska, E.; Negawo, T.A.; Doner, E.; Kilic, A. Lignin as an additive for advanced composites. In Green Biocomposites; Jawaid, M., Sapuan, S.M., Alothman, O.Y., Eds.; Springer: Berlin, Germany, 2017; pp. 71-89.

28. Da Rosa, T.S.; Trianoski, R.; Michaud, F.; Belloncle, C.; Iwakiri, S. Efficiency of Different Acetylation Methods Applied to Cellulose Fibers Waste from Pulp and Paper Mill Sludge. J. Nat. Fibers 2020, 1-14. [CrossRef]

29. ASTM. ASTM D638-14, Standard Test Method for Tensile Properties of Plastics; ASTM International: West Conshohocken, PA, USA, 2015.

30. ASTM. ASTM D790-17, Standard Test Methods for Flexural Properties of Unreinforced and Reinforced Plastics and Electrical Insulating Materials; ASTM International: West Conshohocken, PA, USA, 2017.

31. ASTM. ASTM D570 Standard Test Method for Water Absorption of Plastics; ASTM International: West Conshohocken, PA, USA, 1998. 
32. Méndez, A.; Fidalgo, J.; Guerrero, F.; Gascó, G. Characterization and pyrolysis behaviour of different paper mill waste materials. J. Anal. Appl. Pyrolysis 2009, 86, 66-73. [CrossRef]

33. Kwon, E.E.; Lee, T.; Ok, Y.S.; Tsang, D.C.; Park, C.; Lee, J. Effects of calcium carbonate on pyrolysis of sewage sludge. Energy 2018, 153, 726-731. [CrossRef]

34. Li, X.; Lv, Y.; Ma, B.-G.; Wang, W.-Q.; Jian, S.-W. Decomposition kinetic characteristics of calcium carbonate containing organic acids by TGA. Arab. J. Chem. 2017, 10, S2534-S2538. [CrossRef]

35. Xu, W.; Li, S.; Whitely, N.; Pan, W.-P. Fundamentals of TGA and SDT. 2005. Available online: https://ruc.udc.es/dspace/ bitstream/handle/2183/11485/CC-80\%20art\%201.pdf (accessed on accessed on 25 January 2021).

36. Li, M.; Fu, Q.-L.; Zhang, Q.; Achal, V.; Kawasaki, S. Bio-grout based on microbially induced sand solidification by means of asparaginase activity. Sci. Rep. 2015, 5, 16128. [CrossRef] [PubMed]

37. Kai, D.; Chow, L.P.; Loh, X. Lignin and Its Properties. In Solution Combustion Synthesis of Nanostructured Solid Catalysts for Sustainable Chemistry; World Scientific: Singapore, 2018; pp. 1-28.

38. Schlee, P.; Hosseinaei, O.; Baker, D.; Landmér, A.; Tomani, P.; Mostazo-López, M.J.; Cazorla-Amorós, D.; Herou, S.; Titirici, M.-M From Waste to Wealth: From Kraft Lignin to Free-standing Supercapacitors. Carbon 2019, 145, 470-480. [CrossRef]

39. Sahoo, S.; Misra, M.; Mohanty, A.K. Enhanced properties of lignin-based biodegradable polymer composites using injection moulding process. Compos. Part A Appl. Sci. Manuf. 2011, 42, 1710-1718. [CrossRef]

40. Spiridon, I.; Leluk, K.; Resmerita, A.M.; Darie, R.N. Evaluation of PLA-lignin bioplastics properties before and after accelerated weathering. Compos. Part B Eng. 2015, 69, 342-349. [CrossRef]

41. Chen, S.; Lin, S.; Hu, Y.; Ma, M.; Shi, Y.; Liu, J.; Zhu, F.; Wang, X. A lignin-based flame retardant for improving fire behavior and biodegradation performance of polybutylene succinate. Polym. Adv. Technol. 2018, 29, 3142-3150. [CrossRef]

42. Zhang, J.; Fleury, E.; Chen, Y.; Brook, M.A. Flame retardant lignin-based silicone composites. RSC Adv. 2015, 5, 103907-103914. [CrossRef]

43. Xing, W.; Yuan, H.; Zhang, P.; Yangab, H.; Song, L.; Hu, Y. Functionalized lignin for halogen-free flame retardant rigid polyurethane foam: Preparation, thermal stability, fire performance and mechanical properties. J. Polym. Res. 2013, 20, 234. [CrossRef]

44. Wang, W.; Sain, M.; Cooper, P. Study of moisture absorption in natural fiber plastic composites. Compos. Sci. Technol. 2006, 66, 379-386. [CrossRef]

45. Lekatou, A.; Faidi, S.; Ghidaoui, D.; Lyon, S.; Newman, R. Effect of water and its activity on transport properties of glass/epoxy particulate composites. Compos. Part A Appl. Sci. Manuf. 1997, 28, 223-236. [CrossRef]

46. Dhakal, H.; Zhang, Z.; Richardson, M. Effect of water absorption on the mechanical properties of hemp fibre reinforced unsaturated polyester composites. Compos. Sci. Technol. 2007, 67, 1674-1683. [CrossRef]

47. Tita, S.; Medeiros, R.; Tarpani, J.; Frollini, E.; Tita, V. Chemical modification of sugarcane bagasse and sisal fibers using hydroxymethylated lignin: Influence on impact strength and water absorption of phenolic composites. J. Compos. Mater. 2018, 52, 2743-2753. [CrossRef]

48. Stiubianu, G.; Nistor, A.; Vlad, A.; Cazacu, M. Modification of water sorption capacity of polydimethylsiloxane based composites by incorporation of lignin. Mater. Plast. 2011, 48, 289-294.

49. Thielemans, W.; Wool, R. Kraft lignin as fiber treatment for natural fiber-reinforced composites. Polym. Compos. 2005, 26, 695-705. [CrossRef]

50. Pääkkönen, E.; Wikström, L.; Peltola, H.; Valta, K.; Retulainen, E. Recycled fibres and fibrous sludge as reinforcement materials in injection moulded polypropylene (PP) and poly(lactic acid) (PLA) composites. J. Bioresour. Bioprod. 2017, 2017, 116-122.

51. Betancourt, N.G.; Cree, D.E. Mechanical Properties of Poly (lactic acid) Composites Reinforced with CaCO3 Eggshell Based Fillers. MRS Adv. 2017, 2, 2545-2550. [CrossRef]

52. Guermazi, N.; Haddar, N.; Elleuch, K.; Ayedi, H.F. Effect of filler addition and weathering conditions on the performance of PVC/CaCO3composites. Polym. Compos. 2015, 37, 2171-2183. [CrossRef]

53. Huda, M.S.; Mohanty, K.; Drzal, L.T.; Schut, E.; Misra, M. “Green” composites from recycled cellulose and poly (lactic acid): Physico-mechanical. J. Mater. Sci. 2005, 40, 4221-4229.

54. Valente, M.; Tirillò, J.; Quitadamo, A.; Santulli, C. Use of recycled milled-paper in HDPE matrix composites Marco. Compos. Part B Eng. 2016, 110, 520-529. [CrossRef] 